\title{
A stitch too far: The circumflex artery in jeopardy during mitral valve repair
}

\author{
Jeswant Dillon, MD, FRCS
}

\author{
From the Department of Cardiothoracic Surgery, National Heart Institute, Kuala Lumpur, Malaysia. \\ Disclosures: Author has nothing to disclose with regard to commercial support. \\ Received for publication June 15, 2017; accepted for publication June 19, 2017 \\ Address for reprints: Jeswant Dillon, MD, FRCS, Department of Cardiothoracic Surgery, National Heart Institute, \\ 145 Jalan Tun Razak, Kuala Lumpur 50400, Malaysia (E-mail: jeswant@ijn.com.my). \\ J Thorac Cardiovasc Surg 2017;154:1621-3 \\ $0022-5223 / \$ 36.00$ \\ Copyright (c) 2017 by The American Association for Thoracic Surgery \\ http://dx.doi.org/10.1016/j.jtcvs.2017.06.056
}

\section{"Well, as you know, I always felt we tried to go a bridge too far." \\ -British Lieutenant-General Frederick Browning, deputy commander of the First Allied Airborne Army, on the failure of Operation Market Garden during World War II. From the book and movie, $A$ Bridge Too Far}

Mitral valve repair (MVR) is the preferred choice of treatment to correct mitral regurgitation, especially in cases of degenerative leaflet prolapse. The benefits of repair are well established and include survival advantage, preservation of left ventricular function, and avoidance of anticoagulation. In addition, MVR is one of the few known procedures able to restore normal life expectancy. ${ }^{1}$ The surgery itself is a safe procedure, with an operative mortality of $1 \%$ reported in the Society of Thoracic Surgeons database. ${ }^{2}$ As good as it is, however, mitral surgery is not immune to specific iatrogenic complications arising from the intimate anatomic relationship of the mitral annulus to the surrounding structures, such as acute aortic incompetence, circumflex artery injury, and heart block. ${ }^{3-5}$

Circumflex artery injury after MVR is best avoided, because if it is undetected, it most certainly leads to devastating consequences. The article in this issue of the Journal by Coutinho and colleagues ${ }^{6}$ is a timely reminder of the importance of recognizing the occurrence of this injury and the need for prompt remedial action to limit its potentially catastrophic effects. This article is a worthy addition to the literature in several aspects. First, the startling fact remains that this complication does indeed occur. Coutinho and colleagues ${ }^{6}$ quote an incidence of $0.3 \%$ but acknowledged that it may be as high as $1.8 \%{ }^{7}$ This should alert mitral repair surgeons both that this is not an infrequent iatrogenic complication and that it has potentially disastrous consequences. Second, Coutinho and colleagues ${ }^{6}$ are to be commended for an honest and unbashful report of this series, because there is often an inherent natural reluctance by many to publish negative results. Because of this diffidence and the added difficulty in diagnosis, the true incidence of attention.

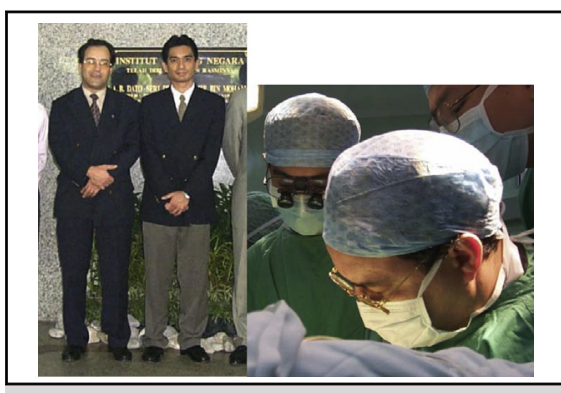

Manuel Antunes (left) and Jeswant Dillon, MD, FRCS (right), National Heart Institute, Kuala Lumpur, 1998 MVR at NHI.

\section{Central Message}

Circumflex artery injury after mitral repair is a disastrous complication. Precise surgical technique, rapid diagnosis and treatment are crucial to avoid potentially fatal myocardial infarction.

See Article page 1613 .

circumflex artery injury may conceivably be much higher than generally perceived. This article is also important because it defines the patients at risk. Of the 6 cases in the series, 5 had a left dominant or co-dominant coronary artery anatomy. The reported percentages of left dominant and balanced anatomy in the literature are $9.8 \%$ and $13 \%$, respectively, ${ }^{8}$ a statistic that emphasizes that almost a quarter of patients undergoing MVR are potentially at risk of circumflex injury and certainly warrants strict

This article is limited by the small number of cases. Nonetheless, the cases are well described, with clear illustrations. One of the key messages derived is the dire consequence of iatrogenic circumflex artery injury. Of the 6 patients with this complication, 4 had severe left ventricular dysfunction resulting in heart transplantation, aneurysm formation or recurrent severe mitral incompetence. The 2 patients who escaped deleterious effects had prompt treatment that reversed potentially disastrous sequelae. The lessons learned here are that we must be consciously wary to avoid this complication and, equally importantly, we must be prompt with diagnosis and remedial strategies to prevent lasting damage to the left ventricle.

The importance of careful surgical technique must be reiterated to all surgeons performing MVR. Cautious annuloplasty suture placement in the danger area of the anterior commissure and its adjacent P1 segment must be 


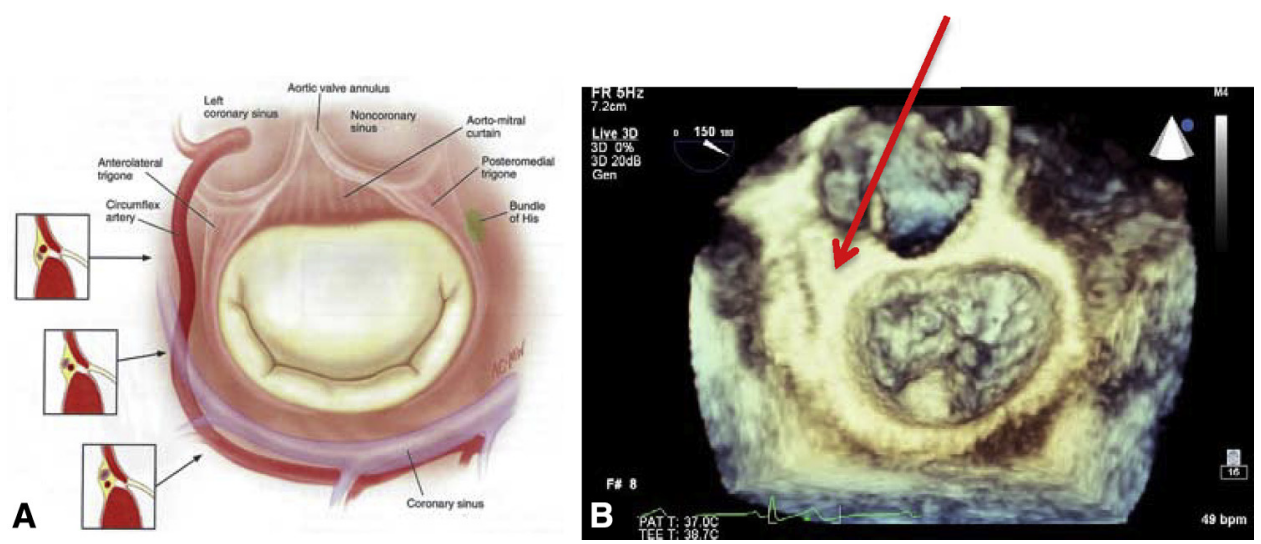

FIGURE 1. A, Diagram illustrates careful suture placement at anterior commissure to avoid circumflex artery. Reprinted with permission. ${ }^{10} \mathrm{~B}$, As demonstrated on 3-dimensional transesophageal echocardiography (arrow).

emphasized, with the suture being not more than $2 \mathrm{~mm}$ away from the annulus, ${ }^{9}$ the needle oriented toward the ventricle,${ }^{10}$ and the avoidance of deep bites. "A stitch too far or too deep" could put the circumflex artery in jeopardy and the patient in deep peril! In addition, we should avoid wide leaflet resection and small annuloplasty rings in the dilated degenerative annulus, because these may crimp the annulus, leading to tissue distortion.

Prompt diagnosis of this complication is crucial in saving myocardium at risk. Transesophageal echocardiography (TEE) is a mandatory part of the MVR procedure. The postrepair TEE detection of decreased contractility and new regional wall motion abnormality should sound the alarm bells. Ender and colleagues ${ }^{11}$ demonstrated the use of intraoperative TEE in 110 patients to visualize the circumflex artery with a combination of B-mode imaging and color Doppler with different Nyquist limits. ${ }^{11}$ Murugesan and associates ${ }^{12}$ further reported on a case of circumflex artery injury after MVR, which was diagnosed and intervened solely with the aid of TEE without performing coronary angiography. The introduction of 3dimensional TEE provides another avenue for identifying the circumflex artery in real time (Figure 1). A recent study by Bevilacqua and coworkers ${ }^{13}$ illustrated that measurements of horizontal and vertical distances of the circumflex artery to the mitral annulus can be performed with real-time 3-dimensional TEE and showed good correlation with multidetector computed tomography-based measurements. It is thus now possible to demonstrate accurately the flow within the artery with color Doppler and the anatomy of the artery with 3-dimensional transesophageal echocardiography in a large proportion of patients. It is conceivable to recommend that intraoperative TEE study for MVR should include the identification of the circumflex artery and the exclusion of flow limitations after repair. As diligently as we interrogate for iatrogenic systolic anterior motion, perhaps the complete control TEE examination after MVR should be routinely extended to exclude iatrogenic circumflex injury.

Finally, the authors from Coimbra ${ }^{6}$ deserve congratulations for reminding us of and reeducating us on this potentially fatal iatrogenic surgical complication. More than anything, it should increase our awareness that it does occur not insignificantly, and we must take all efforts to prevent it and act immediately to prevent acute myocardial infarction. I could not agree more that our cardiothoracic fraternity should set up a multicenter registry to trace the true prevalence and make crucial recommendations to prevent this dreadful complication.

\section{References}

1. Enriquez-Sarano M, Schaff HV, Orszulak TA, Tajik AJ, Bailey KR, Frye RL. Valve repair improves the outcome of surgery for mitral regurgitation. A multivariate analysis. Circulation. 1995;91:1022-8.

2. Gammie JS, Sheng S, Griffith BP, Peterson ED, Rankin JS, O'Brien SM, et al. Trends in mitral valve surgery in the United States: results from the Society of Thoracic Surgeons Adult Cardiac Surgery Database. Ann Thorac Surg. 2009; 87:1431-7; discussion 1437-39.

3. Kolakalapudi P, Chaudhry S, Omar B. Iatrogenic aortic insufficiency following mitral valve replacement: case report and review of the literature. J Clin Med Res. 2015;7:485-9.

4. Grande AM, Fiore A, Massetti M, Viganò M. Iatrogenic circumflex coronary lesion in mitral valve surgery: case report and review of the literature. Tex Heart Inst J. 2008;35:179-83.

5. Viles-Gonzalez JF, Enriquez AD, Castillo JG, Coffey JO, Pastori L, Reddy VY, et al. Incidence, predictors, and evolution of conduction disorders and atrial arrhythmias after contemporary mitral valve repair. Cardiol J. 2014;21:569-75.

6. Coutinho GF, Leite F, Antunes MJ. Circumflex artery injury during mitral valve repair: not well known, perhaps not so infrequent lessons learned from a sixcase experience. J Thorac Cardiovasc Surg. May 23, 2017 [Epub ahead of print].

7. Aybek T, Risteski P, Miskovic A, Simon A, Dogan S, Abdel-Rahman U, et al. Seven years' experience with suture annuloplasty for mitral valve repair. $J$ Thorac Cardiovasc Surg. 2006;131:99-106.

8. Singh S, Ajayi N, Lazarus L, Satyapal KS. Anatomic study of the morphology of the right and left coronary arteries. Folia Morphol (Warsz). May 29, 2017 [Epub ahead of print].

9. Pessa CJ, Gomes WJ, Catani R, Prates JC, Buffolo E. Anatomical relationship between the posterior mitral valve annulus and the coronary arteries. Implications to operative treatment. Braz J Cardiovasc Surg. 2004;19:372-7. 
10. Carpentier A, Adams DH, Filsoufi F. Carpentier's reconstructive valve surgery: from valve analysis to valve reconstruction. Philadelphia: Saunders; 2010.

11. Ender J, Selbach M, Borger MA, Krohmer E, Falk V, Kaisers UX, et al. Echocardiographic identification of iatrogenic injury of the circumflex artery during minimally invasive mitral valve repair. Ann Thorac Surg. 2010;89: 1866-72.
12. Murugesan C, Raghu B, Rao PV. Transesophageal echocardiographic diagnosis and management of circumflex artery injury following mitral valve repair. Car diol Res. 2011;2:90-2.

13. Bevilacqua C, Eibel S, Foldyna B, Knoefler T, Lehmkuhl L, Gutberlet M, et al Analysis of circumflex artery anatomy by real time 3D transesophageal echocardiography compared to cardiac computed tomography. Int J Cardiovasc Imaging. May 13, 2017 [Epub ahead of print]. 